\title{
EL CASO DEL CUENTACUENTOS \\ (Publicidad y ficción, ficción y publicidad)
}

\section{Pedro Vidal Silva ${ }^{1}$ \\ Universidad Complutense de Madrid \\ pvidal@ccinf.ucm.es}

Material original autorizado para su primera publicación en la revista académica REDMARKA. Revista Digital de Marketing Aplicado.

https://doi.org/10.17979/redma.2013.01.011.4746

Recibido: 15 Octubre 2012

Aceptado: 10 Diciembre 2012

\section{Resumen}

La publicidad, emergida en la modernidad, adopta inicialmente, en su manifestación más habitual, la forma de la ciencia, es decir la de un discurso argumentativo. Pero la saturación y falta de eficacia hacen buscar nuevas posibilidades expresivas. Adopta, entonces, la forma de relato. Pero con el tiempo esos relatos de ficción transcienden la acción individual de cada mensaje y pasan a conformar un corpus, de naturaleza ideológica, que altera la función principal que la publicidad cumple en las sociedades que han ido un paso más allá de la posmodernidad.

Metodológicamente se hace un sucinto repaso a los distintos sujetos del sistema en su relación con el tópico de cabecera, en su doble manifestación mutua.

Palabras clave: marca, creatividad, ficción.

\footnotetext{
${ }^{1}$ PEDRO VIDAL SILVA (Madrid, 1952) es profesor de Creatividad Publicitaria en la Facultad de Ciencias de la Información. Profesor Titular de la Universidad Complutense.
} 


\section{Abstract (inglés)}

THE STORYTELLER CASE. (PUBLICITY AND FICTION, FICTION AND PUBLICITY)

Advertising, emerged in modernity, initially adopted in its most usual manifestation, the form of science, namely an argumentative discourse. But saturation and inefficiency do find new expressive possibilities. Adopts then the story form. But over time these fictional stories transcend the individual action of each message and come to form a corpus, ideological, altering the primary role that advertising plays in societies that have gone a step beyond postmodernism.

Methodologically is a brief review of the different subjects of the system in relation to the topic header, both as mutual manifestation.

Key words: brand, creativity, fiction.

\section{Resumo (portugués)}

Publicidade, surgiu na modernidade, adotado inicialmente na sua forma mais comum de ciência, ou seja, um discurso argumentativo. Mas o congestionamento $e$ ineficiência que encontrar novas possibilidades expressivas. Adota então a forma de história. Mas com o tempo essas histórias ficcionais transcender a ação individual de cada mensagem e vir a formar um corpus, ideológica, alterando o papel principal que desempenha publicidade em sociedades que foram um passo além do pós-modernismo.

Metodologicamente é uma breve revisão dos diferentes sujeitos do sistema em relação ao cabeçalho do tema, tanto como manifestação mútua.

Palavras-chave: marca, criatividade, ficção. 
No sé nada de espíritus; yo vivo en mis sueños. Las demás personas también viven en sueños, pero no en los suyos propios; esa es la

diferencia.

Hermann Hesse (en Demian)

\section{Introducción}

En la base del mito, el relato de ficción es el tipo de discurso dominante entre los humanos. Rigorizado en su estructura y funcionamiento desde la poética de Aristóteles, su fundamento está en la mimesis.

La ficción, en su forma genérica de relato, ha sido y sigue siendo el modo de transmisión de información principal en todas las culturas ${ }^{2}$; reconocible en cualquiera de sus codificaciones, incluidas las visuales ${ }^{3}$.

Al relato de ficción, al igual que al mensaje persuasivo en la retórica clásica, se le pueden asignar las funciones de docere, delectare y moveré4. Es por esto por lo que también lo adopta la publicidad. Más aún últimamente, al desplazarse esta, en una era que podríamos denominar postpublicitaria ${ }^{5}$, hacia el dominio trascendente del relato hierofánico ${ }^{6}$ y hagiográfico de las religiones.

\section{El fundamento de la ficción}

Es bien sabido que el concepto de ficción proviene de la Grecia clásica y, tal como lo cuenta Enrique Anderson Imbert (Teoría y técnica del cuento), en su etiquetación deriva del verbo latino fingere, que significa fingir, simular. Una

\footnotetext{
2 Tal como lo reconocen antropólogos, lingüistas del texto, historiadores, sociólogos, etnometodólogos, etc.

${ }^{3}$ Tanto Piaget como Bruner, entre los psicólogos evolutivos, han comprobado que el recuerdo para relatos funciona igual en su codificación visual. En el caso español Gema Paniagua y Álvaro Marchesi han investigado al respecto.

${ }^{4}$ Son las tres funciones básicas del mensaje persuasivo y que se pueden traducir como enseñar, divertir y motivar.

${ }^{5}$ Esta noción de postpublicidad no coincide con la que sostiene Daniel Solana en su libro de igual título.

${ }^{6}$ Mircea Eliade llama hierofanía a cualquier manifestación de lo sagrado.
} 
simulación de la realidad presente en la mayoría de las manifestaciones consideradas artísticas de los humanos ${ }^{7}$.

Pero el fundamento de la ficción está en la mímesis, en el aprendizaje por imitación, mecanismo este que mantiene su continuidad en muy diversos niveles de la escala filogenética, principalmente en los más altos ${ }^{8}$. Es la función principal que desde la biología evolutiva (los neodarwinistas) se le atribuye. Principalmente Denis Dutton ${ }^{9}$.

La ficción sería, así, una continuación especulativa, de naturaleza adaptativa, del aprendizaje mimético ${ }^{10}$. Una variación supervivencial que altera sistemáticamente algún elemento, en una conducta imitativa, con fines de entrenamiento en situaciones proyectivas, potencialmente futuras.

La ficción nos entrena las emociones. Y éstas, como dice Daniel Góleman ${ }^{11}$, nos permiten hacer las cosas más deprisa, sin pensar, heurísticamente, y acertando la mayoría de las veces. El entrenamiento emocional es fundamental para la vida. Sea un entrenamiento directo, vivencial, o indirecto, virtual o proyectivo, a través de la ficción.

No es extraño, así, ver su manifestación en la mayoría de las actividades e interacciones que realizan los humanos desde pequeños. Es el tipo de conducta que aparece en casi todos los juegos infantiles, que van preparando y predisponiendo al infante para la mayor parte de las tareas de la vida adulta, lo que parece un mecanismo antecedente adecuado para la adaptación a cualquier entorno vivencial. Pero también para la asunción de los papeles (estereotipados) que la sociedad asigna a tales tareas lo que, a partir de nuestra conciencia moderna, parece menos adecuado, al minorar, por ejemplo,

\footnotetext{
${ }^{7}$ Entre las modalidades de arte mimético cabría mencionar la danza, la escenificación de la conducta animal, la pintura rupestre, etc., entre las antiguas, y todo el arte actual según los teóricos de la estética.

${ }^{8}$ Riedl, R. (1983).

${ }^{9}$ Dutton, D.(2010) (Recientemente fallecido)

10 Aprendizaje por imitación que tanta importancia tuvo en el conductismo, para el establecimiento de hábitos.

${ }^{11}$ Goleman, D. (1996)
} 
el papel asignado a las mujeres, y considerarlas exclusivamente como madres nutricias $^{12}$.

\section{3. ¿Por qué funciona la ficción?}

El mecanismo que hace tan efectiva ${ }^{13}$ a la ficción es la identificación con el personaje. El buen funcionamiento de ese fenómeno de masas que fue Harry Poter, se debió a que todo niño quería ser como el mago protagonista. Descubrían a través del prota el mago que íntimamente había en ellos mismos. A las niñas les gustaba su timidez, que inspiraba sentimientos encontrados de protección y admiración al mismo tiempo, pero también se proyectaban en su amiga Hermion.

Ortega y Gasset decía que "a los españoles para persuadirles, primero hay que seducirles". Nos habla, así, de dos regímenes distintos. La persuasión, consistente en convencer a alguien mediante argumentos, y la seducción, que actúa mediante un mecanismo diferente, como es el caer bien, gustar personalmente, relacionarse a nivel afectivo. Tal como comprobamos en la vida cotidiana es más fácil que nos convenza alguien que nos cae bien, y que nos parece simpático. Es lo relativo al pathos, el término que la retórica utiliza para referirse a los sentimientos. Así en todas las lenguas, pero principalmente en las romances (las provenientes del latín) y, sobre todo, en castellano, existen multitud de términos relacionados con esta forma de relación afectiva: simpatía, a-patía, anti-patía, em-patía, com-padecer. Llagándose al caso extremo de que algo puede estallar por simpatía.

\footnotetext{
${ }^{12}$ Esta perpetuación de papeles se ve claramente aún en la mayoría de los anuncios infantiles. Es por ello por lo que se instituyó en su día el premio Casandra, del Ministerio de Asuntos Sociales, que premiaba la publicidad no sexista de juguetes.

13 Debemos distinguir entre efectividad, eficacia y eficiencia. Normalmente en publicidad se habla sólo de la segunda, en lo relativo a la medición de resultados, pero las tres son pertinentes. Efectividad se refiere a la consecución de los efectos buscados. La eficacia al buen funcionamiento del recurso utilizado. Y la eficiencia a la cantidad de recurso necesario para el logro de los efectos. Así, a menor cantidad, mayor eficiencia.
} 
Para que funcione, entonces, el personaje de un relato de ficción debe mostrar una empatía que nos lo haga parecer simpático y permita, de este modo, la proyección afectiva, el ponernos en su lugar. Es una de las manifestaciones de la apelación sentimental o afectiva, que la hace tan eficaz.

En el terreno de la investigación de la persuasión, este ámbito es el relativo a las características de la fuente, que tan pormenorizadamente se investigó en los años sesenta, sobre todo en la escuela de Yale. Hovland, McGuire, Triandris, por mencionar sólo a tres de aquellos investigadores, son referencias obligadas, en las que sería excesivo abundan en este artículo, al ser piedras angulares o sine qua non.

Pero hay un terreno no tan conocido de investigación como es el del aprendizaje por modelos. Aquí, estudiosos como Bandura y Walters llevaron a cabo investigaciones sobre el aprendizaje de la violencia, a través de los modelos que mostraban los medios, con un mecanismo que podríamos denominar de improntación, y que a la postre desembocó en la actual teoría del cultivo.

Pero hay más. Esa proyección emocional que hace tan efectivo el uso de personajes de ficción con una finalidad de influencia (persuadir, seducir, modelar), ha hecho a lo largo de la historia que las sociedades ágrafas, esto es, aquellas que no escriben y que se transmiten su cultura de forma oral, recurran al relato (mitológico, en la mayoría de las ocasiones) para transmitir todos sus conocimientos útiles y funcionales de una generación a otra. Aquello que les permite perpetuarse en el territorio en el que les ha tocado vivir. Es lo que, desde Malinowski (padre de la antropología moderna) se han encontrado los antropólogos. Multitud de relatos morales (de mores, que significa 
costumbres) que, en forma de un gran panegírico cultural, contenían todo el conocimiento relativo a una etnia o cultura ${ }^{14}$.

Incluso en las ciencias del lenguaje existe un sistema cuya finalidad es evitar que se pierdan esos relatos, cuando desaparece el último miembro de una etnia. El antropolingüista Kenneth L. Pike fue el creador de la tagmémica, una suerte de gramática que permite recoger de forma sistemática todos estos tópicos, partiendo de una estructura base y sus diversas variaciones ${ }^{15}$.

\section{Ficción y realidad}

El camino en pos del conocimiento seguido por occidente nos ha llevado de la ficción del mito a la empiricidad de la ciencia, esto es, a una forma constatíva de entender lo que nos rodeaba y que hemos llamado realidad ${ }^{16}$. Este logro de la modernidad que supuso, en palabras de Nietzsche, la muerte de los dioses, no ha hecho desaparecer la ficción mitológica sin embargo. Tal como expone Jean François Lyotard ${ }^{17}$, los humanos necesitamos ciertos relatos que fundamenten nuestro modelo de mundo y nuestras creencias ${ }^{18}$.

La muerte de los dioses conlleva que nos creamos otras ficciones, que construimos para eliminar el desequilibrio resultante en la cognición humana (disonancia). Así, las nociones modernas de estado, ciencia, y otras equivalentes que nos hicieron romper con viejos modelos del mundo, necesitan de un relato subyacente y coherente que las legitime, más poderoso que el modelo lógico que explícitamente las sustenta.

\footnotetext{
${ }^{14}$ Es la interesantísima vía seguida por la microsociología y, sobre todo, la etnometodología.

15 Pike, Kenneth L. (1967)

${ }^{16}$ Es lo que puede corresponder al logos en la visión tradicional, como forma de discurso sobre la realidad.

17 Lyotard (1987)

${ }^{18}$ Los relatos legitimadores de Lyotard. Lyotard (1987)
} 
Tras la muerte de los dioses, por las ranuras del féretro en que los enterramos salen de nuevo los mitos. Las viejas historias de trascendencia, que implican la existencia de entidades protectoras que dan cobertura al hombre, que se ha quedado sólo con su razón en la modernidad. Ficciones o invenciones para no morir de miedo

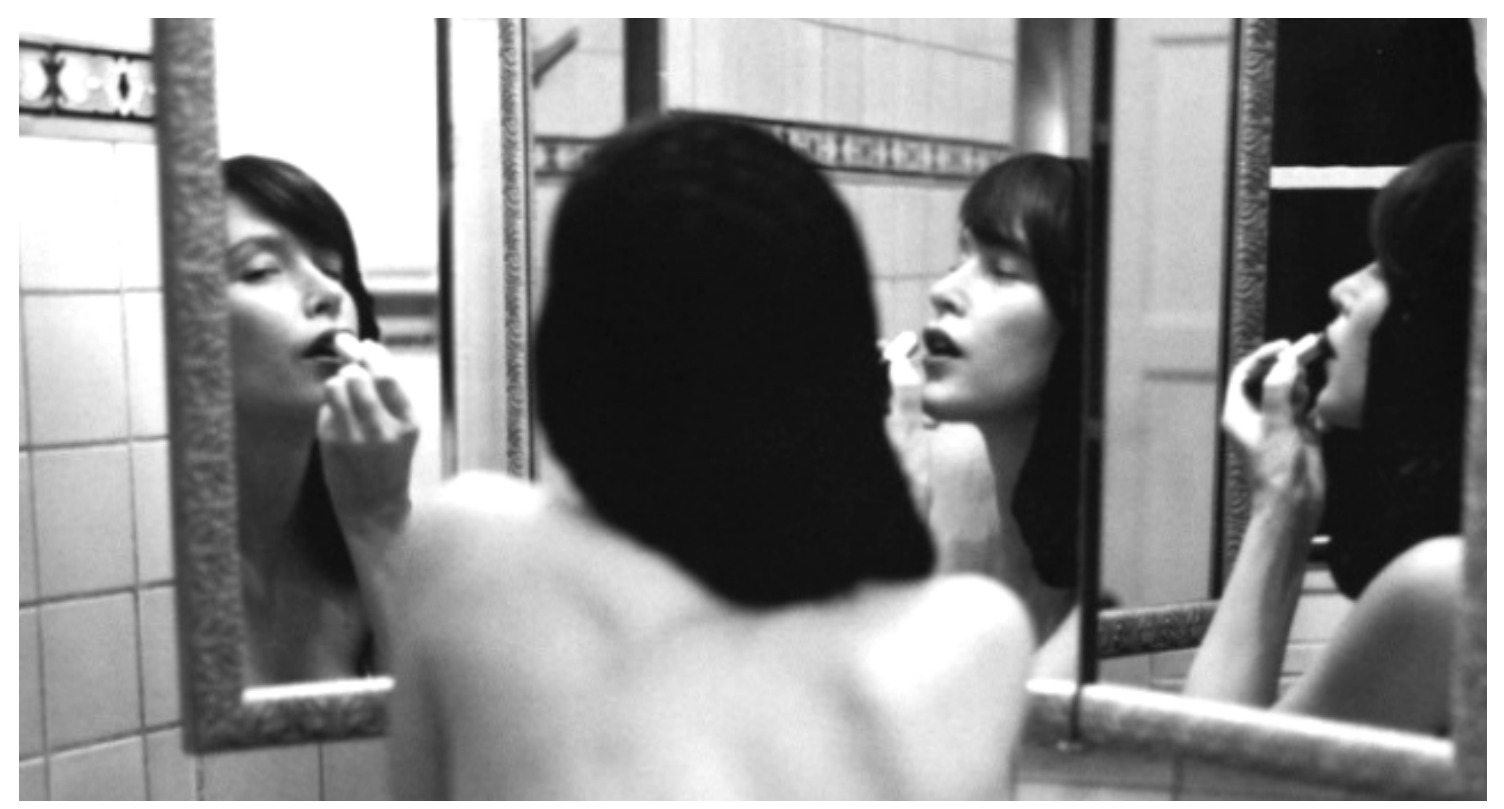

ante la soledad que la arrogancia de la razón nos deja. Grandes mentiras sustentadoras de nuestro equilibrio y estabilidad. Un buen ejemplo de ello es el relato "El Señor de las Moscas" de William Golding, que desde un punto de vista antropológico (este premio Nobel de literatura siempre lo hace en su relatos) muestra lo fácil que es el camino inverso del logos al mythos ${ }^{19}$.

La noción de realidad (que no de verdad) es un constructo convencional como muchos otros ${ }^{20}$, que depende del modelo de mundo (como conjunto de creencias) del que partamos. En la tesis solipsista, donde conocer la realidad es imposible, esta, la realidad, es una ficción más, conveniente para el sueño de la razón que es la existencia humana ${ }^{21}$.

Fuera de esta hipótesis, podemos constatar que necesitamos la ficción para vivir, necesitamos que nos mientan, el fingimiento. Incluso lo pedimos

\footnotetext{
${ }^{19}$ Golding, W. (1972)

${ }^{20}$ Véase como ejemplo otro concepto convencional como es el tiempo en Howking, S (2001).

${ }^{21}$ El tópico se ha renovado en el cine. Desde Matrix, de los Wachofski, hasta Abre los Ojos, de Alejandro Amenábar
} 
desesperadamente, como en Johnny Guitar ${ }^{22}$, cuando el protagonista le dice a Vienna (el personaje interpretado por Joan Crawford): "Miénteme. Dime que me has esperado todos estos años. Dímelo."23

Aunque se trate de metaficción, nada mejor que esto para entender el pacto ficcional. Perfectamente codificado y protocolizado a nivel cultural, el pacto con la ficción supone que se suspende la contrastabilidad de lo enunciado durante la recepción. Y se activa la noción de mundo posible ${ }^{24}$ como contrafactual de lo empirizable, en aras de la obtención de algún beneficio: aprendizaje, entretenimiento, ayuda en la toma de decisiones, ejemplificación (moralizante), consuelo ante algún desasosiego, etc.

\section{Ficción y verdad}

Una vieja campaña institucional española proclamaba que "donde hay publicidad resplandece la verdad". Aunque ese exceso hiperbólico no sea cierto, lo parece aún menos cuando se usa la narración frente a la argumentación que, hasta la renovación estratégica de los años sesenta, fue la herramienta fundamental de la publicidad. No así en literatura, donde la ficción puede ser la forma poética de la verdad, entendida en el sentido mimético de reflejo del alma humana. La ficción, así vista, puede ser una gran mentira utilizada para contar verdades como puños.

En relación a la percepción humana de la verdad, la forma que esta adquiera parece importante. Por eso el relato (la organización cronológica de los datos) parece peor soporte de la verdad que la argumentación (la organización lógica

\footnotetext{
${ }^{22}$ Película de 1954 de Nicholas Ray.

${ }^{23}$ Por su pertinencia para lo expuesto, se reproduce a continuación el fragmento completo del diálogo entre Johnny y Vienna:
}

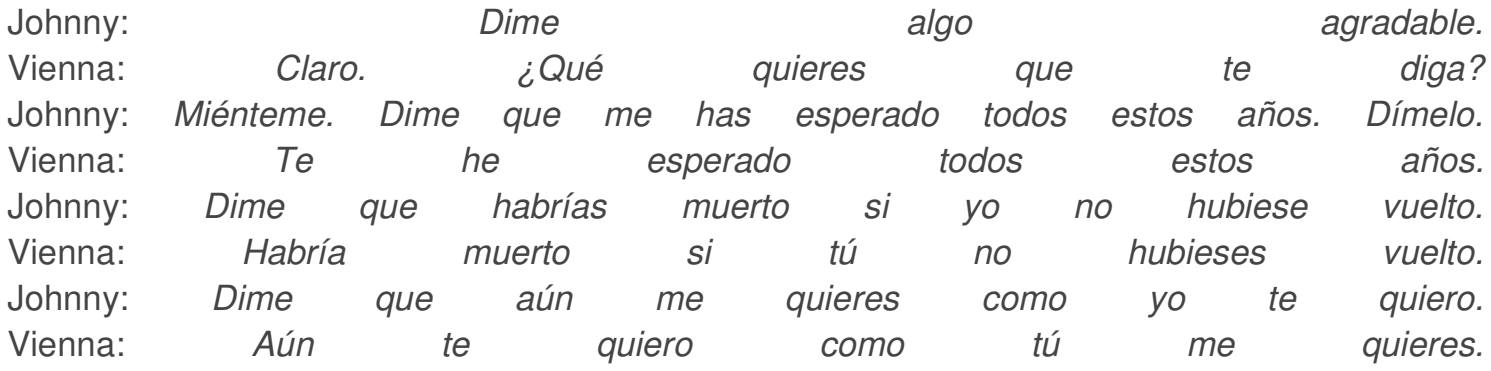
Johnny. Gracias .... Muchas gracias.

${ }^{24}$ El concepto de mundo posible en Petöfi, J. (1979) 
de estos). Al menos es así desde que, con la modernidad, la ciencia, en busca de rigor y derivabilidad optó por la organización lógica de la información. Esto es más cierto para las ciencias consideradas duras, como la física, que para las ciencias humanas, menos formalizadas al respecto.

La verdad, que está en la base de los sistemas apofánticos de la lógica formal, es el asentamiento de la semántica de los lenguajes naturales en su versión más tradicional, la constatíva empiricista, que empareja los enunciados con la información factual perceptible. Existen, así, solamente dos valores de verdad, verdadero o falso. Lo no empírico, al menos conocido, hace rechazar como verdadero el referente, entrando en este saco toda invención no constatable empíricamente, como es el caso de la ficción. Aunque sea un caso de nivel conceptual. Lo ficcional puede corresponder a un grado de verdad relativo en relación a un prototipo (concepto), frente a otros ejemplares constatables. Es algo que resuelve la semántica de prototipos $^{25}$, al plantear un ejemplar privilegiado (prototipo), con todos los atributos, respecto al cual se sitúan el resto de ejemplares, a mayor o menor distancia.

La ficción sería así el caso de un ejemplar no empirizable de un concepto que si lo es (el prototipo). $\mathrm{O}$, como dije antes, un ejemplar inexistente (falso) de un concepto verdadero.

La hija bastarda de la lógica, la teoría de la argumentación, mostrando la misma apariencia que esta, es sin embargo el instrumento de influencia adoptado inicialmente por la publicidad, como consecuencia de su emergencia en el tiempo de la razón. La publicidad preferirá posteriormente la estructura narrativa como instrumento más poderoso de influencia, que decrementará sin embargo su apariencia de verdad.

\section{Las relaciones complejas de la publicidad y la ficción}

Las razones por las que la publicidad se relaciona con la ficción son múltiples, y pretendo en este artículo realizar un repaso por las principales, sin por ello caer en el enciclopedismo. Dejaré para el final la relación inversa, esto es, cuando la publicidad se inserta en la ficción como mecanismo estratégico en su búsqueda

${ }^{25}$ Kleiber, G. (1995) 
de la eficacia o cuando funciona, como un referente temático más, en el ámbito ficcional.

Con pretensión de sistematicidad, habrá que plantear el uso de la noción de ficción en los diferentes sujetos del sistema publicitario. Veremos así que la manifestación que podría considerarse más justificable y abundante, como es la creativa en la elaboración de mensajes, está condicionada por elementos antecedentes. Vayamos pues de sujeto en sujeto, empezando por el anunciante.

\section{El nuevo concepto de marca}

Las marcas ya no son los productos fiables de una empresa a los que un nombre da cobertura, para diferenciar a unos productos de los de su competencia en la categoría. Ni tampoco, como en los años 80, una imagen nimbada, o aureolada (como anticipara David Ogilvy $^{26}$ ) que, frente a los atributos (valores de uso), genera identidad y preferencia en las decisiones adquisitivas de los consumidores.

Las marcas son historias. Narraciones que sostienen las creencias en torno a tales marcas. Historias reales y negativas, como las de explotación infantil en la fabricación de sus productos, que perjudicaron a Nike (y otras marcas de las consideradas desde entonces sucias). O contrahistorias ficcionales que, a modo de El Gran Hermano de Orwell, cambian la historia real ${ }^{27}$. Relatos de ficción al fin y al cabo, que buscan la adhesión a la causa que sostiene tal historia.

Las marcas son, hoy día, relatos con una moraleja, de naturaleza ética, que tienen la misma estructura que las fábulas, de enfrentamiento y lucha de valores. Construidas por guionistas, que lo mismo fabulan un mito del origen de la marca, que una Arcadia futura.

\footnotetext{
${ }^{26}$ David Ogilvy es el padre de la estrategia conocida como imagen de marca

27 El antecedente visual lo encontramos en Stalin que, a través de los fotomontajes de Gustav Kluzis, cambiaba la historia real al ir eliminando a sus adversarios políticos.
} 
Es por ello por lo que algunos denominan a esta situación capitalismo de ficción ${ }^{28}$, sustentado en historias y no en balances bursátiles.

Estamos en la era de la empresa proyecto donde algunas terminan siendo, nada más que, un Power Point ${ }^{29}$. Tal proyecto puede contarse con la descripción y explicación del lenguaje científico (las menos), o en forma de relato en la, actualmente, denominada orientación del Storytelling ${ }^{30}$.

Para ello las empresas contratan a expertos en el arte narrativo. Desde guionistas de Hollywood hasta cuentacuentos. Incluso los, en otras ocasiones denostados, analistas del lenguaje adquieren ahora relevancia y son mimados por las empresas para que les desvelen los secretos de la naturaleza de los relatos. Por extraño que pueda sonar, el Análisis estructural del relato ${ }^{31}$ o las diversas gramáticas de relatos existentes ${ }^{32}$ se han convertido en auténticos superventas.

Si este es el concepto de sí misma que preconiza la empresa anunciante, condicionará, sin lugar a dudas, la tarea de construcción de mensajes publicitarios, referidos tanto a la entidad como a los productos o servicios que oferta. Es una cuestión de coherencia comunicativa.

\section{La ficción en la creatividad publicitaria}

La elaboración de mensajes publicitarios ha estado siempre condicionada por la base estratégica de la que se partía, entendiendo por tal una representación del consumidor sustentada por el paradigma psicológico del momento.

Así cuando la psicología sostenía, en coherencia con la economía, que el consumidor era racional la forma de influir sus decisiones era con razones o, en su dimensión técnica, con argumentos. A los creativos, para elaborar los mensajes, se les dotaba de un instrumento como la copy stratgy, que no era más que una herramienta para enseñarles a argumentar.

\footnotetext{
${ }^{28}$ Verdú, V. (2003)

${ }^{29}$ Fromer, F. (2011)

30 Salmon, Ch. (2008)

${ }^{31}$ Barthes, R. (1981)

32 Propp, V.(1981).Stein y Glenn y otros en Vidal, P. (1985)
} 
En esta etapa, como he apuntado antes, el aspecto de los mensajes publicitarios era el de enunciados contrastables. Esto es de propuestas coincidentes o cercanas al mundo de la realidad y con un grado determinado de verdad (al menos si no consideramos los anuncios más hiperbólicos). Las demostraciones, como variante de la publicidad argumentativa, conferían un aspecto de verosimilitud a los mensajes difícil de alcanzar de otras maneras. Era el mundo de la evidencia, y evidencia viene de videre que, según Aristóteles, es lo que podemos ver con nuestros propios ojos. No hay mejor argumento que la evidencia.

Pero el consumidor racional no era más que un desideratum que los nuevos paradigmas psicológicos descartaron. Así el psicoanálisis representó a un sujeto que, lejos de toda racionalidad, se mueve por motivaciones profundas. Esta visión influyó considerablemente el mundo de la publicidad, que encontró en la investigación de motivaciones (con metodologías proyectivas) un auténtico filón. El consumidor ya no era racional. Era un sujeto movido por sus pasiones y estas difícilmente son argumentables.

Es el salto de un consumidor racional a uno emocional que exige nuevas estrategias constructivas. Pero no sólo eso, es el paso, también, de la persuasión, alcanzable mediante argumentos, a la seducción, donde son herramientas más adecuadas lo relatos de ficción, y más aún si se codifican con imágenes.

Surgen así estrategias como la, antes mencionada, Imagen de Marca, en la que David Ogilvy no renuncia a la invención de personajes para la elaboración de ficciones que exalten los productos de una marca. Incluso sigue la vía de la iconología griega, la clásica, a la hora de construir los personajes. Los dota de un atributo singular (por ejemplo un parche en el ojo para las camisas Hataway) que les dé relevancia y significado. En el fondo el resultado es el mismo que en el caso griego, la antropomorfización de un concepto abstracto que representa los valores de la marca.

Pero no es la única. Hay muchas otras estrategias, de las genéricamente llamadas emocionales, que están incluso mejor adaptadas para la construcción 
de ficciones. Es el caso de El Drama Inherente que, a propuesta de Leo Burnett, obliga al creativo a encontrar una historia de la marca (o el producto) que no sólo lo justifica sino que, y esto es importante, lo poetiza. Se anticipa con ello a la versión actual del storytelling tal como ahora lo entienden los anunciantes.

Posiblemente el ejemplo más exitoso de esta estrategia ficcional sea la campaña de Marlboro, para muchos la mejor de la historia de la publicidad.

No es cuestión de extenderse más allá de lo razonable, pero muchas otras estrategias de esa época, a un lado y otro del Atlántico, indujeron a los creativos a la vía ficcional. Habría pues que mencionar el Impacto Emocional, propuesta por quien liderara la Revolución Creativa de la publicidad norteamericana, William Bernbach, que pretendía con sus historias, y una codificación dominantemente visual, atraer a unos consumidores cada vez menos racionales, no porque lo dijese la psicología, sino porque una situación de abundancia, como era la posterior a la guerra en Norteamérica, incrementa enormemente la oferta y hace difícil la elección por razones objetivas. Es el momento en que, parafraseando a Orwell, todos los productos son iguales pero algunos son más iguales que otros ${ }^{33}$. Y la diferenciación no puede consistir en listados de atributos improcesables, mediante comparación entre todos ellos a fin de maximizar los beneficios obtenibles, por los consumidores. Es por ello por lo que la vía de lo simbólico se impone como preferible, y en este terreno el relato gana claramente al argumento.

También en Europa, aunque posteriormente, la vía de la ficción es la prioritariamente elegida. Como botón de muestra sirva el ejemplo de la Star Strategie de Jaques Segélà ${ }^{34}$, en donde el creativo francés propone una gran metáfora para la elaboración de los mensajes. Considera antropomórficamente las marcas y, como las grandes estrellas de Hollywood, las dota de una personalidad, expresable mediante un estilo o puesta en escena. Personalidad construida y ficcional que, como un personaje necesitado de expresión, debe hacerse visible en cada anuncio de la marca.

\footnotetext{
33 Orwell, G. (1973).

${ }^{34}$ Séguéla, J. (1991)
} 
Otro ejemplo europeo es el de la Dramatización de lo Simple, de John Hegarty, uno de los genios de la creatividad europea, que propone que el mejor anuncio es aquel que dramatiza una característica del producto, su principal atributo de posicionamiento, en forma de una historia sencilla, donde los valores más simples y emocionales se vean implicados, de manera que todo el mundo pueda comprender, cómo los relatos de la Mid-Cult de las sociedades desarrolladas.

Como puede verse, la ficción entra de lleno en el proceso creativo publicitario en un momento en que el producto era aún importante, pero que el exceso de oferta hace abandonar en beneficio de una representación más económica, genérica y recordable, como es la marca.

Marca que, una vez construida simbólicamente, puede dar cobertura a infinidad de atributos indiferenciables de otra manera. Es el salto del atributo al concepto, de la función al significado y este, como nos enseñaron los griegos es mejor representarlo como personaje y construir historias que lo hagan visible y creíble.

Es lo que hicieron para visibilizar conceptos como la agricultura, la aritmética o la justicia. Por eso Paul Klee decía que la función del arte es hacer visible lo invisible. Parece también una buena estrategia para que el consumidor comprenda y recuerde conceptos que de otra forma serían difíciles de comunicar. Es el paso de la ingeniería material, la de los atributos físicos y funcionales, a la ingeniería semántica, la de los significados, más engranables en el sentido que la gente pretende para sus vidas.

Un buen ejemplo de cómo un concepto abstracto, que sirve de posicionamiento a la marca, puede hacerse visible mediante un relato de ficción, es la magnífica campaña que durante tantos años mantuvo Jack Daniel's. En ella se codificaba el concepto de tiempo, que transcurriendo lentamente, y según la estrategia, hacía posible el sabor inigualable del producto. Tanto en gráfica como en audiovisual, una sucesión de relatos intranscendentes, contados en blanco y negro, transmitieron la idea de que el tiempo ralentizado era la seña de identidad del pueblo en el que se elaboraba el brebaje. 


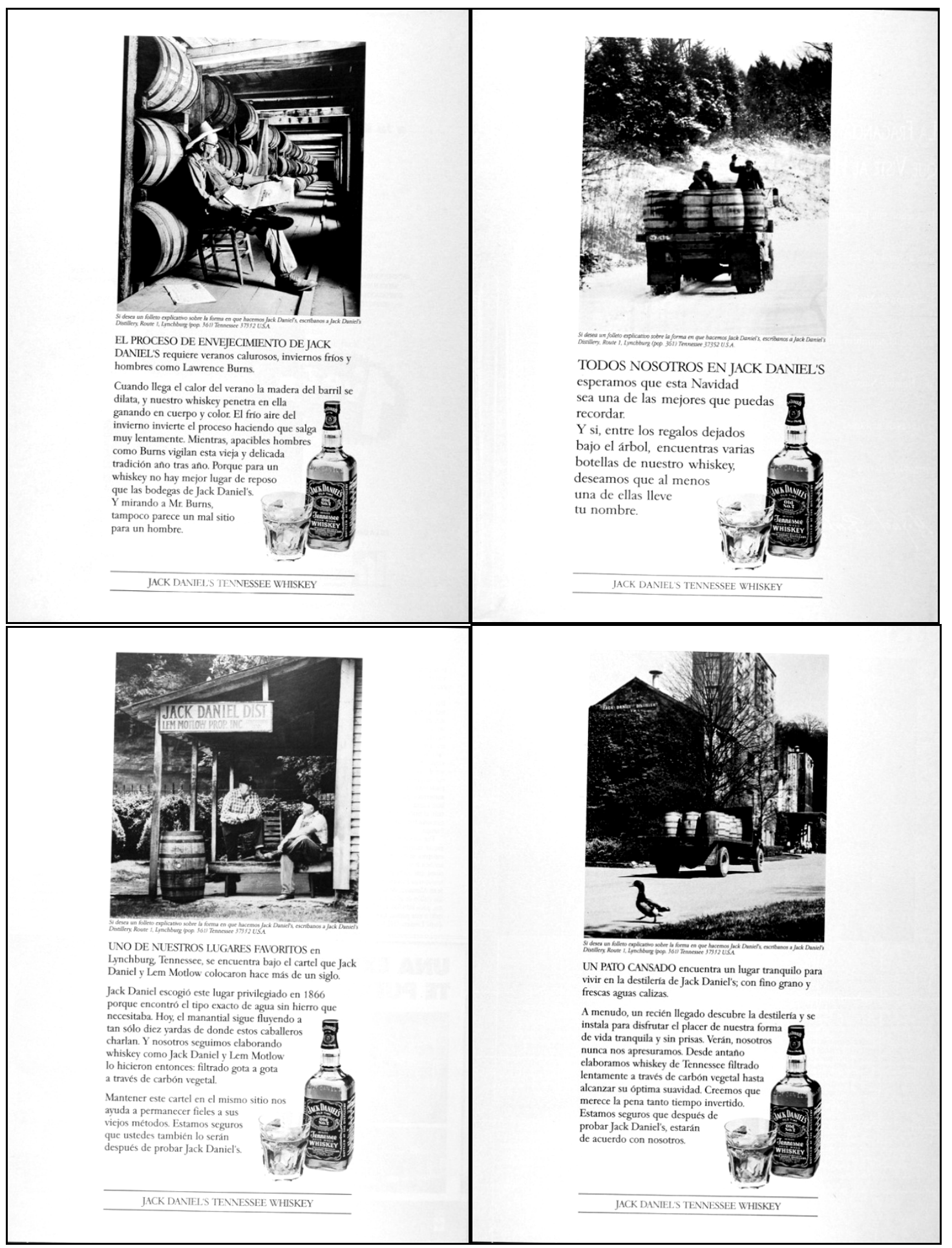

De estas estrategias de elaboración de mensajes se deriva que el creativo publicitario sea, en la mayoría de las situaciones productivas, un a modo de cuentacuentos, un storyteller en terminología anglosajona, un fabulador que ha sustituido las herramientas del orador por las del cuentista.

\section{La labor del cuentacuentos}

REDMARKA UIMA-Universidad de A Coruña - CIECID 
Muchas empresas, internacionales y nacionales, siguieron esta vía de narrar historias inducidas por las estrategias emocionales. Baste recordar las magníficas campañas de Cola Cao en los años 80, o las de Seat en los 70, donde un médico podía atender a una parturienta en un pueblo, conduciendo por caminos horribles, porque llegaba con un Seat 600.

La diferencia es que antes eran historias del usuario (consumidor/exhibidor) del producto, y ahora es la historia de la marca, o de sus fundadores, como creadores de la empresa y de la propia marca, lo que se cuenta ${ }^{35}$.

Es una especie de texto sagrado que cuenta la historia revelada de un concepto transcendente. Una historia de valores enfrentados y de héroes defendiendo el lado positivo. De sus triunfos, de sus aportaciones al beneficio común ( $¿$ ?), de su épica.

Texto sagrado que se entrega por capítulos, en el contenido de las distintas campañas, y que sirve tanto para la publicidad como para las relaciones públicas y todas las restantes formas de comunicación de una empresa/marca con sus diferentes públicos, en un planteamiento de coherencia y comunicación integrada.

Sólo las grandes religiones tienen una manifestación igual, donde un ThinkTank (centro estratégico), llamése el Vaticano o la Meca, planifica y diseña el referente que contendrán los distintos mensajes, adaptados a los diversos lugares y posibilidades vehiculares (medios y soportes). Ellos fueron los primeros en pensar en global y actuar en local.

Con la muerte de los dioses y la emergencia del estado moderno, al nuevo dios-estado se le trató de igual manera. Se antropomorfizó, como los griegos habían enseñado, creando un estado con cara y ojos, que en su extremo más abstracto era el Leviatán de Hobbes $^{36}$, monstruo marino legendario de la tradición judía, que simbólicamente representaba un referente constituido por todos los individuos de un estado, pero cuyo poder transcendía con creces al

\footnotetext{
${ }^{35}$ Es como escribir la historia de los Anunnaki, la raza madre de dioses uránicos que, provenientes de algún lugar del espacio, nos diseñaron, según las diversas mitologías.

${ }^{36}$ Hobbes, T. (1980)
} 
de sus individuos y grupos ${ }^{37}$. $Y$ en el otro extremo, el más concreto, es el representado por la figura de Luis XIV de Francia, "L'etat c'est moi". Construido discursiva y simbólicamente por todo el sistema de las artes, las letras y las ciencias de Francia, operando al unísono, para la elaboración de un discurso que concretarse para la población la imagen del estado. ${ }^{38}$

Podemos considerar así que la invención de Luis XIV es la primera gran campaña de imagen institucional de la historia (imagen de la marca Francia de entonces).

Es el modelo que, aunque ellos no lo sepan, están siguiendo en la nueva orientación del storytelling las grandes empresas multinacionales, las más poderosas económicamente pero que sustentan su valor en ese intangible transcendente. Han llegado, también, a la conclusión que "es de necio confundir valor y precio".

\section{El consumidor y la ficción}

Desde un punto de vista funcional, la ficción (el relato de ficción, las historias) es una estructura más adaptada al almacenamiento de información en la memoria. Es una cuestión de sentido o pertinencia de los datos.

La investigación psicológica de la memoria demostró que lejos de almacenar la información en forma de listas, como pretendían los conductistas, al individuo le resulta más fácil recordar los datos si estos están organizados en forma de una historia con sentido. Fue Barttlet ${ }^{39}$ quien cambió el paradigma de investigación, al percibir como, en todos los protocolos de recuerdo, éste se incrementaba notablemente al pasar de las listas de palabras aleatorias (como material experimental que debía memorizarse) a cuentos, con una estructura comprensible para el sujeto experimental.

Y la memoria de los consumidores es uno de los grandes problemas con los que se enfrenta la publicidad en su búsqueda de la eficacia. Es una de las

\footnotetext{
${ }^{37}$ Algo con lo que el grupo de Bilderberg no está de acuerdo y pretende acabar encerrando a éste monstruoso Leviatán en una jaula económica para exhibirlo en sus fincas privadas.

38 Burke, P. (2003)

${ }^{39}$ Barttlet, F.C. (1968)
} 
justificaciones pragmáticas de la utilización del relato frente a la argumentación o los listados de atributos.

No obstante, esta vía que a través de la ficción accede al Pathos del consumidor no siempre es la más adecuada según la teoría. Todo dependerá del nivel de implicación que suponga la categoría, esto es, de la importancia emocional que ésta tenga para los valores importantes del sujeto. Medible a través de un concepto indirecto como puede ser el riesgo percibido (en el uso de la categoría), riesgos que pueden ser desde físicos hasta sociales y profesionales $\mathrm{o}$, incluso, de construcción del autoconcepto. A mayor riesgo percibido mayor implicación. Dicho de otra forma, hay categorías cuyo uso nos puede causar problemas. Tomar decisiones respecto a las mismas conlleva manejar y comparar información, es decir, datos. Es la base de la toma racional de decisiones, el manejo consciente de información relevante que nos permita decantarnos por la mejor opción (la más beneficiosa, o, en su defecto, la menos perjudicial). Así, no fiaríamos a un relato la decisión respecto a una máquina herramienta con la que nos la jugamos profesionalmente. O la salud de nuestro bebé a la hora de elegir su alimentación.

Pero estas categorías, frente al total de la oferta en los países desarrollados, son cada vez menos importantes. Y aún siendo también de alta implicación, al ser el modo de expresar el autoconcepto, las categorías más visibles socialmente, las de consumo conspicuo en terminología de $V_{e b l e n^{40}}$, si se prestan a su publicitación ficcional mediante el relato.

\section{La memoria para relatos}

Considerada la niña bonita de la investigación psicolingüística, en el ámbito de los procesos cognitivos, la memoria para relatos ha sido el ámbito donde lingüistas y psicólogos han podido intercambiar modelos ${ }^{41}$. Surge así un dominio de investigación y teorización que aporta no pocos beneficios a la planificación estratégica del mensaje publicitario.

\footnotetext{
${ }^{40}$ Veblen, T. (2004)

${ }^{41}$ Vidal, P. (1985)
} 
Ya en las partes artis de la retórica aristotélica, la narratio inducía a exponer el referente, sobre el cual se intentaba convencer, en forma de relato. Es decir la narración (ficcional) en el seno de la persuasión.

Con el concepto de esquema, aportado inicialmente por Barttlet, se concreta la organización que los relatos adoptan en la memoria de los individuos y que es coincidente con lo que los teóricos del lenguaje han venido desde siempre estableciendo. De ahí la posibilidad de aprendizaje y utilización por parte de los distintos profesionales implicados en el storytelling, como apunté anteriormente.

Lo que es claro es que, según se deriva de todas las investigaciones, tanto niños como adultos prefieren el relato como modalidad expresiva, también en publicidad. En los niños facilita la comprensión (aunque muchos procesos interactivos con la madre les vayan entrenando en la comprensión de la argumentación ${ }^{42}$ ) y en los adultos, además, el recuerdo. Esto hace que el relato, principalmente en su modalidad de ficción, demuestre su eficacia frente a otras modalidades expresivas de la publicidad. Esto no impide reconocer que no sea siempre lo mejor para un desarrollo pleno y consciente del pensamiento.

En general se está perdiendo la capacidad de argumentar y del razonamiento lógico que permite no sólo un conocimiento más riguroso, e infalsificable, del mundo, sino también un mayor control en la acción sobre el mismo. Las nuevas tecnologías propician, de la mano de la imagen y el concepto de multitarea (múltiples pantallas abiertas para operaciones con una escasísima profundidad de procesamiento), lo que Augusto Curry denomina SPA, o síndrome del pensamiento acelerado, lo que no sólo genera ansiedad sino también un conocimiento muy superficial de las cosas.

\section{El consumidor como personaje}

Otra forma de relacionar al consumidor con la ficción es considerar cómo se le representa desde el marketing. Los perfiles que del consumidor incorporaban las estrategias más habituales los representaban de una manera fría, como un

${ }^{42}$ Vidal, P. (1986) 
simple listado de características. Esto cambió radicalmente con la llegada de $V_{A L S}{ }^{43}$. Un tipo de investigación que desde Stanford proporcionó retratos robot de los consumidores a las empresas y a los creativos publicitarios. Y para hacerlos visibles hubo que construirlos como personajes de ficción, dotándolos de un hombre y describiendo un día completo de sus vidas ${ }^{44}$. Al fin y al cabo una ficción que los hiciese representables.

Esta forma de presentación inducía, sin duda, a incluir a tales personajes en las dramatizaciones que del uso del producto pudieran hacerse. No sólo los describía ideológica y emocionalmente, propiciando así su mejor y más pertinente representación publicitaria, sino que facilitaba su uso en todo tipo de guiones. Era como el retrato de los personajes que algunos escritores pinchan ante sus ojos en las mesas donde escriben para propiciar las tramas en que los involucran. Era la técnica seguida por Juan Rulfo, que como buen fotógrafo que recorrió, cámara en mano, todo Méjico, utilizaba sus propias fotografías para concretar a sus personajes. Algo similar son los retratos robot qué VALS ofrece para la ficcionalizacion publicitaria.

\subsection{El consumidor como personaje de ficción}

Las historias de las marcas, el storytelling, puede hacer que consumamos temáticamente. Esto es, asumiendo un papel y consumiendo las marcas que sean coherentes con el mismo, como ya sugiriese en su día George Ritzer ${ }^{45}$, cuando plantea que en el más alto nivel de la distribución, las que denomina catedrales del consumo, el consumidor se comporta como un personaje que visita un parque temático. La muerte de los dioses nos dio control sobre nuestro destino, pero hizo desaparecer la magia, el encantamiento que, según parece, seguimos necesitando para vivir.

\footnotetext{
${ }^{43}$ VALS es el acrónimo en inglés de valores y estilos de vida.

${ }^{44}$ Algo similar a lo que hiciera Aleksandr Solzhenitsyn en Un día en la vida de Iván Denisovitch.

${ }^{45}$ Ritzer, G. (2000)
} 
En Psicologías del Autor y Lógicas del Personaje ${ }^{46}$, Ricardo Gullón, analizando a Galdós, nos explica cómo logra este autor la coherencia de los personajes en cada historia. Algo parecido a lo que hacen los consumidores en la era actual. Más aún si consideramos con Eric Berne ${ }^{47}$ que el proyecto de vida de cada individuo es como un guión cinematográfico que construimos, proyectivamente, y que conduce la coherencia de nuestra vida en todos los aspectos, también en el ámbito del consumo. No muy lejos está la noción de máscara, como asunción de papeles diferenciales en las distintas situaciones conductuales institucionalizadas de la vida, que sostiene el microsociólogo Erwing Goofman $^{48}$, y que plantea que tras cada una de ellas representamos un papel conveniente a cada situación de interacción. Un protocolo que puede describirse y utilizarse tal como hacen los psicólogos cognitivos de la inteligencia artificial, y que está en la base del desempeño de papeles en multitud de programas expertos, incluidos los juegos de ordenador más complejos, como son los de naturaleza social.

\section{El medio ficción}

Las vanguardias artísticas, en su afán de notorización y visibilidad, recurrieron a las más disparatadas estrategias expresivas, siempre coherentes con el espíritu de innovación específica que las animaba.

Hicieron de las puestas en escena de sus propios miembros la mejor manera de publicitarse. Parte del corpus artístico de dichos movimientos es el relativo a dichas escenificaciones. Así, desde las provocadoras soirées futuristas de Marinetti, o sus intervenciones radiofónicas en busca de la tecnología que amplificase sus "parole en libertá", hasta las performances dadaístas en el Cabaret Voltaire, con aquellos antibelicistas rumanos, como fueron Tristán Tzara y Hugo Ball al frente, ejecutando aquella incomprensible (entonces) poesía fonética, disfrazados con los trajes de papel que ellos mismos se

\footnotetext{
${ }^{46}$ Gullon. R.(1979)

47 Berne, E. (1974)

${ }^{48}$ Goffman, E. (2006)
} 
confeccionaban; por no hablar de las puestas en escena de los surrealistas, 0 las del grupo ZAJ en España, las vanguardias siempre han hecho de la dramatización (ficcionalizacion de la realidad) su mejor herramienta publicitaria. Su infalible medio de difusión y persuasión, dicho sea de paso.

Desde entonces es la forma de publicitarse de multitud de grupos de índole muy diversa, tanto los artísticos como los de una determinada orientación ideológica, y que proliferaron tanto en los años setenta. Es un mecanismo de integración del arte en la realidad, como lo fue, a nivel de representación, el cubismo sintético, al incorporar la realidad del papel impreso a los cuadros de Juan Gris o de Picasso. Es, por iterarlo de nuevo, la realidad ficcionalizada.

Como mezcla de ambas cosas, artistas con ideología manifiesta en una de las tendencias de la postmodernidad, las Guerrilla Girls, utilizan estos mecanismos de escenificación para publicitar sus propuestas ideológico-artísticas.

Vemos, de esta manera, que el medio puede ser un personaje, por supuesto de ficción. Es el medio ficción que anticipaba el título de este apartado. Algo que la publicidad convencional intentará utilizar en la búsqueda de una mayor notoriedad (atencionalidad) para la marca. Al margen del contenido de mensaje que pueda transmitirse, la función fática (en terminología de Jakobson) es cada vez más importante, dado el crecimiento geométrico de mensajes de naturaleza persuasiva en esta sociedad hiperinformada.

Por ello gran parte del esfuerzo creativo en publicidad va destinado a la simple notorización, al hacerse ver. De ahí que entre las nuevas posibilidades comunicativas se incluya la denominada publicidad de guerrilla (guerrilla advertising) que utiliza en su implementación estas invenciones del arte.

Los ejemplos son múltiples. Casi siempre es el sujeto-medio, el performer que, bien asumiendo el aspecto de un personaje de marca (mascota, carácter publicitario), o con un aspecto diseñado para la ocasión, aparece en diversos entornos reales en los que se presente una determinada saturación de público objetivo. Su ejecución se pertiniza como una ficción que dramatiza (y permítanme la grandilocuencia de la expresión que sigue) la epopeya de la marca. 
No muy distinta en su intención es la publicidad basada en inventar acontecimientos para la marca, lo que los franceses inicialmente llamaron publicite evenemenciel, y que aquí preferimos denominar simplemente eventos $^{49}$. Diseñar acontecimientos de marca, que la hagan figurar en la sección correspondiente de noticias, es una forma más de ficcionalizar la realidad, y como consecuencia, de convertir al medio que se haga eco en un medio-ficción ${ }^{50}$.

Indudablemente el medio ficcional por excelencia, al tiempo que medio-ficción, es sin lugar a dudas Internet, donde hasta los más sencillos mecanismos de interacción se codifican visualmente y con un protocolo narrativo. ¿Será la herencia que a toda una generación le dejó Barrio Sésamo? (Serie infantil financiada por Coca-Cola y que adoptó la fragmentación y estructura de los mensajes publicitarios. Todos los contenidos eran pequeños sketchs que lejos de describir el mundo, tal como necesitan los niños, lo ficcionalizaba).

\subsection{Ficción y publicidad}

Aunque suene a Amaral, esta sección comienza "Como Nicolas Cage en Living las Vegas" ${ }^{\prime 51}$, exhibiendo las intimidades de la relación que la publicidad ha tenido con el cine y otros mundos de ficción. $Y$ esa es una de las manifestaciones que se han utilizado para ejemplificar el denominado product placement, los cinco minutos iniciales en que, mientras se acicala ante el espejo, Nicolas Cage (protagonista de la película ${ }^{52}$ ) exhibe, sin pudor alguno, la marca Calvin Klein que aparece bordada en la cinturilla de su slip.

\footnotetext{
${ }^{49}$ Las agencias de eventos se integran actualmente, como una especialización más, en los grupos de comunicación.

${ }^{50} \mathrm{La}$ tendencia social es, a través de los recursos tecnológicos, a ficcionalizar todo el entorno. No es otra cosa lo que hacen las nuevas cámaras fotográficas que, en una de sus posibilidades, sólo toman la foto si la gente está sonriendo. Ni siquiera, de esta forma, podemos constatar la realidad tal cual es. El sistema nos impide hacer visible la tristeza.

${ }^{51}$ El grupo Amaral utiliza esta expresión varias veces en la canción Moriría por vos.

${ }^{52}$ Leaving las Vegas, dirigida por Mike Figgis en 1995.
} 
La falta de eficacia de la publicidad convencional (la denominada above-theline ${ }^{53}$ ), o lo que es lo mismo, la búsqueda de mayor notoriedad, visibilidad y recuerdo, y de paso evitar el rechazo, ha supuesto que se buscasen nuevas posibilidades tanto estructurales, de nuevas formas de mensaje a insertar en los medios de siempre, como nuevas modalidades publicitarias insertables en otros medios. Entre ellas la incorporación de la publicidad, del producto, o de la marca en el resto del contenido de los medios. Algunos de estos contenidos son de ficción, como es el caso de las películas de cine y de las series televisivas, donde la aparición, perfectamente integrada en el guión en los casos en que la acción lo justifique, tanto de un producto como de una marca, provocan no sólo menor rechazo que otras modalidades publicitarias convencionales, sino que incluso tienen un efecto modelizador que supera en eficacia, con creces, a estas otras modalidades.

La posibilidad de integración de la publicidad en estas ficciones no se limita al audiovisual, también la literatura es susceptible de tal incorporación. Así hubo unos años en que las novelas incorporaron marcas, en lugar de productos genéricos en la descripción de la acción de los personajes de una historia. En esos casos frente a una descripción como "... Darío aparcó el coche. Ya en casa arrojó el abrigo sobre la cama antes de encender el que sería el último cigarrillo de la noche...", puede optarse por "... Darío aparcó su flamante BMW. Ya en casa arrojó el Burberry sobre la cama antes de encender el que sería el último Marlboro de la noche...". Agobiante, sin duda, pero a cierta literatura incluso le beneficia, otorgándole un aspecto fashion que puede pertinizarla para ciertos grupos objetivos de lectores.

Otro vehículo ficcional posible es el de las canciones. Esos pequeños relatos que, cuando están bien construidos y responden al espíritu de una generación, son la mejor forma de acceso al pathos de un potencial público objetivo. Los casos son múltiples, tanto de product placement como de brand placement, pero cabe destacar la canción que el grupo santanderino El Norte popularizó

\footnotetext{
${ }^{53}$ Se denominan así a la publicidad que se programa en los medios convencionales, la que metafóricamente está por encima de una supuesta línea de flotación. Correspondientemente se denomina below -the-line a la publicidad que se programa en los nuevos medios y soportes, esto es, por debajo de la línea de flotación.
} 
con el título "Un diamante es para siempre", otro excelente caso de publicidad encubierta para la marca De Beers.

Pero es el cine el que ha mantenido una más larga historia de amor con los estilos de consumo, con los productos y con las marcas. No hace falta remontarse a los orígenes para recordar algunos casos más que notables. Así aquella legendaria camiseta que luciera Marlon Brando en Un tranvía llamado deseo, que supuso una posterior inusitada demanda de tal prenda por la población americana. Igualmente su cazadora de mortero y los vaqueros que luciese en la película Salvaje ${ }^{54}$. Otro caso histórico, quizás sólo en España, es el de la película Rebecca ${ }^{55}$, que dio nombre a la chaqueta de punto que luciera la protagonista y puso de moda el uso de esta prenda.

Y qué decir del agente 007, de su legendario Aston Martín y su no menos exitoso reloj, primero el Rolex Submariner y posteriormente el Omega Seamaster, considerado por muchos como uno de los mejores casos de product placement de la historia.

Aunque sí hay un caso que destaque sobre todos es el de la película Un trabajo en Italia $^{56}$, protagonizada por Michael Cain, película diseñada para exhibir las habilidades de los Minis de la empresa Austin Morris Group, protagonistas exclusivos de la acción en éste prodigioso guión que puede considerarse como un anuncio de hora y media.

Sería prolijo abundar en más ejemplos, tanto cinematográficos cuanto televisivos, pues es un fenómeno creciente en las series de los últimos tiempos, alentadas por los éxitos históricos, como lo hicieron los muebles españoles (de la región de Valencia) en series como Dallas.

Aunque como contrapartida habría que mencionar el prodigioso caso de Los dioses deben estar $10 \cos ^{57}$, uno de los escasísimos casos de cine africano exhibido en nuestro país, película en la que tanto el mythos como el logos occidentales quedan parodiados, sobre todo a través de la acientífica visión

\footnotetext{
${ }^{54}$ Un tranvía llamado deseo (1951), dirigida por Elia Kazan, y Salvaje(1953), película dirigida por László Banedek

${ }_{55}^{5}$ Rebecca (1940), dirigida por Alfrad Hichtcock

${ }_{57}^{56}$ Un trabajo en Italia, dirigida por Peter Collinson en 1969.

${ }^{57}$ Los dioses deben estar locos, dirigida por Jamie Uys en 1980.
} 
antropológica que licita la historia. Es una crítica a toda la ciencia de las humanidades que se practica en occidente. En la película, el bosquimano protagonista intenta arrojar fuera de su mundo, lugar en el que supuestamente viven los dioses, una botella de Coca-Cola, objeto absolutamente desconocido para el protagonista, que ha caído desde el cielo. Tal vez no sea tan disparatada la idea de la totemización de ciertas marcas. Es la idea de la publicidad como epifanía de la hierofanía que supone la presencia de tales marcas en la sociedad actual, y de su construcción transcendente a través del, ya citado, storytelling.

\subsection{La publicidad como referente de la ficción}

Quizás sólo faltaría, tras este brevísimo repaso al tópico del monográfico, mencionar una última posibilidad de relación entre la ficción y la publicidad. Es cuando esta aparece como referente o tema destacado en las diversas modalidades ficciones. La lista de películas referidas a la publicidad es interminable, lo mismo que el personaje de algunas históricas series televisivas. Baste recordar a aquel ingenuo y poco ocurrente marido de la bruja protagonista de Embrujada (con una revisión cinematográfica reciente). Aunque la exitosa serie Mad Men haya eclipsado los últimos años a todos sus antecedentes.

Entre las películas desde Pijama para dos o Un, dos,tres, entre las más clásicas, hasta Gente loca y Noviembre dulce, de tiempos más recientes, la lista es tan grande que considerando las distintas visiones (anunciante, agencia, público objetivo, o incluso los medios) podría constituir un género en sí mismo (las ad movies), ténganlo en cuenta historiadores y teóricos. Aunque es sólo una sugerencia. El género estaría más fundamentado si estas ad movies se integrasen en uno más amplio que incluyese el poder y funcionamiento de los medios, porque el periodismo sí que es un referente indiscutible en la historia del cine.

También la literatura de ficción ha utilizado a la publicidad como territorio de acción, lugar donde la presión laboral hiperboliza los males y tics de nuestra 
sociedad, fundamentalmente de la vivencia urbana, siendo el referente para un nuevo retrato costumbrista. Pero el abundamiento en esta línea tendrá que esperar a otra ocasión.

\section{A modo de conclusión}

El nuevo orden económico mundial, donde todo el control está en una Empresa Mundial S.A. ${ }^{58}$, utiliza a la publicidad para ficcionalizar la realidad, con las técnicas de las grandes empresas adscritas al grupo (Apple, Pepsico, etc.) como el storytelling, creando así una nueva ideología alienadora de las masas $^{59}$.

Es como el Gran Hermano de Orwell. Una historia de la humanidad inventada que nos hace creer, con nuevas fabulaciones (ficcionalizaciones) y con la ayuda, también, del cine de Hollywood ${ }^{60}$, que vivimos en un mundo perfecto cuyo orden debemos acatar.

La ficcionalizacion en la publicidad ha supuesto el acceso a una forma de influencia muy poderosa, hasta ahora sólo reservada a las religiones ${ }^{61}$ y a los ideólogos. Pero esa es la función de la publicidad en el Nuevo Orden Económico Mundial. Una función ideológica que sustituye al papel que en su día tuvieron las religiones en la vida del hombre.

La religión es la mayor ficción jamás contada, en cualquiera de sus variantes, aunque sobre todo en las monoteístas. Es, además, la más articulada: referentes sacros, textos sagrados, protocolos estables y explícitos (ritos, epifanías), historia del origen, expectativas de un futuro glorioso, estilo de vida prescrito, etc.

Hermann Hesse, en una de sus novelas, decía a través de la boca de un personaje que "quien cree en una religión y acepta sus preceptos es que es lo suficientemente vago como para no crearse un mundo propio independiente,

\footnotetext{
${ }^{58}$ Entiendase el grupo de Bilderberg, con D. Rockefeller a la cabeza.

${ }^{59}$ Con recursos tecnológicos como la viralidad, que da sensación de antisistema cuando en realidad es lo contrario, al estar controlado el medio por esa nueva superestructura. Nunca fue más cierta la teoría persuasiva de la inoculación.

${ }^{60}$ Hollywood forma parte de la antedicha Empresa Mundial S.A. y Nicolas Cage revisando hasta la historia constatada es sus películas. Estulin, D. (2008)

${ }^{61}$ Construcción de los mitos transcendentes uránicos, según Mircea Eliade.
} 
con sus propias verdades y no las que otros les imponen" (no es una cita literal).

Algo similar le ocurre al consumidor actual, la falta de tiempo y la complejidad del mundo le inducen a adoptar un estilo de vida prediseñado, pret a porter. Ante un mundo cada vez más secularizado y descreído ¿por qué no adoptar el que nos propone una de las grandes marcas? y de paso recuperar:

*la creencia en algo transcendente

*la pertenencia a un grupo

*una expectativa diseñada de futuro

*unas señas de identidad que, de otra forma se pierden ante la complejidad del mundo.

*etc.

¿Qué diferencia hay entre este tipo de conductas de consumo y las derivadas de las creencias religiosas? Las grandes marcas se comportan como religiones y nos hacen: mantenernos fieles, respetar las celebraciones, no utilizar el nombre de la marca en vano, participar en ritos y oficios, compartir experiencias con el resto de creyentes, reforzar y difundir la comunidad, etc.

En la ficcionalizacion publicitaria, la imagen juega un importante papel. Frente a la publicidad argumentativa (la de la era de la razón) basada en atributos y beneficios que apelaban al sujeto racional, la imagen genera relato y ficción. Apela a las emociones e impide el razonamiento. Son dos sistemas contrapuestos. Como en la política, la imagen genera el ídolo, el tótem ${ }^{62}$.

El relato que la publicidad (entendida como sistema, como industria cultural) pasa como modelo global al individuo, para su perfecta integración y consecución de las metas definidas por el sistema, es el de trabaja-callaconsume-sé feliz. $\mathrm{Y}$ lo hace a través de paquetes ficcionales (modelos de consumo/estilos de vida) que le sirven de diseño o modelo de realidad. No está

\footnotetext{
${ }^{62}$ Cruz Revueltas J.C. (2009).
} 
muy lejos de lo que ya en su día anticipara la escuela de Fráncfort ${ }^{63}$, el espíritu es el mismo, pero han cambiado las técnicas y las tecnologías.

De este modo, como ya ocurriera anteriormente, la publicidad integra y frivoliza la contracultura, como hace con toda revolución ${ }^{64}$. La cultura de masas (la industria cultural) es como una enorme masa de pan, que unos cuantos amasan, y que absorbe como tropezones las distintas iniciativas contraculturales y revolucionarias. Homogeneizándolo todo y devolviéndolo en forma de rebanadas horneadas y listas para su consumo: anuncios, moda, visitas guiadas, paquetes turísticos, programas de televisión, documentales, etc. que vacían la intención contracultural inicial, su sentido original, y lo cosmetizan.

La función de la ficción en publicidad, en la actualidad, es pues desactivar la protesta, integrándola en la gran masa (torta) cultural, de carácter cada vez más global ${ }^{65}$.

Les ha costado mucho, a los amos del mundo, fragmentarnos el pensamiento de esta manera. La gente, así, atiende a una parcela cada vez más pequeña del proceso total. Divertida y fácilmente procesable, pero pierde la visión global al estar desarticulada. Es incapaz de insertar el fragmento en un todo al faltarle la idea de estructura, de sistema. Para eso hace falta otra forma de pensamiento que ellos sí tienen y que, con las tecnologías y el bombardeo informativo, le hurtan a los demás ${ }^{66}$. Quieren que vivamos del cuento.

Es posible que Calderón de la Barca tuviera razón cuando, anticipatoriamente, nos decía...

\footnotetext{
¿Qué es la vida? Un frenesí.

¿Qué es la vida? Una ilusión, una sombra, una ficción,
}

\footnotetext{
${ }^{63}$ Marcuse, H.(1968)

${ }^{64}$ La comuna de Berlín terminó cuando sus líderes se suicidaron o montaron una boutique. Algo parecido ocurrió con el punk.

${ }^{65}$ Colonización cultural, medios controlados por macro-operadores poderosos dependientes de la superestructura, etc.

${ }^{66}$ Es lo que está pasando también en la enseñanza, donde el cacharrero tecnológico fragmenta y desmembra contenidos, haciendo perder la visión global de los sistemas y propiciando un contacto planetario que, como añagaza, intenta suplir al primero.
} 


$$
\begin{aligned}
& \text { y el mayor bien es pequeño; } \\
& \text { que toda la vida es cuento, } \\
& \text { y los cuentos, cuentos son. }
\end{aligned}
$$

Espero que sepan ustedes disculparme la licencia.

\section{Bibliografía}

Barthes, R. (1981) Introduction a L'analyse structurale du récit. Paris. Ed. Seuil. Barttlet, F.C. (1968) Remembering. Cambridge. Cambridge University Press. Berne, E. (1974) ¿Qué dice usted después de decir hola? La psicología del destino humano. Barcelona. Editorial Grijalbo.

Burke, P. (2003) La fabricación de Luis XIV. San Sebastian. Ed. Nerea. Cruz Revueltas, J.C. (2009) Imagen ¿signo, icono o ídolo? Mexico. Ed. Siglo $X X I$.

Dutton, D. (2010) El instinto del arte.Barcelona. Ed. Paidos.

Eliade, M. (1972). Tratado de historia de las religiones (Vol. 11). Ediciones Era Estulin, D. (2008) La historia definitiva de El Club Bilderberg. Barcelona. Ed.Planeta.

Fromer, F. (2011) Power Point. Ensayo sobre un programa que nos vuelve estúpidos. Barcelona. Ed. Península.

Goffman, E. (2006) Frame Analisis.Madrid. Ed. S.XXI.

Golding, W. (1972), El Señor de las moscas. Madrid. Ed. Alianza.

Goleman, D. (1996) Inteligencia emocional. Barcelona.Ed. Kairós.

Gullon. R.(1979) Psicologias del autor y lógicas del personaje. Madrid. Ed.

Taurus.

Hobbes, T. (1980) Leviatán. Mexico. Fondo de Cultura Económica.

Howking, S. (2001) Historia del tiempo. Madrid. Ed. Alianza.

Imbert, E. A. (1979). Teoría y técnica del cuento. Marymar. 
Kleiber, G. (1995) La semántica de los prototipos. Madrid. Ed. Visor. Lausberg, H. (1983). Manual de retórica literaria, vol. I. Madrid: Gredos. Lyotard, J. (1987) La condición postmoderna. Madrid. Ed. Cátedra. Marcuse. H. (1968) El hombre unidimensional. Barcelona. Ed. Seix Barral. Orwell, G. (1973) Rebelion en la granja. Barcelona. Ed. Destino Petöfi, J. (1979) Text versus sentence. Hamburgo. Ed. Buske. Pike, Kenneth L. (1967). Language in relation to a unified theory of the structure of human behavior. Vol. 32 en Janua Linguarum, Series Maior. La Haya: Mouton.

Propp, V. (1981) Morfología del cuento. Madrid. Ed. Fundamentos.

Riedl, R. (1983) Biología del conocimiento. Barcelona. Ed. Labor.

Ritzer, G. (2000) El encanto de un mundo desencantado. Barcelona. Ed. Ariel.

Salmon. Ch. (2008) Storytelling. Barcelona. Ed. Península.

Séguéla, J. (1991) Holliwwood lava más blanco. Barcelona. Ed. BBB.

Solana, D. (2010). Postpublicidad: reflexiones sobre una nueva cultura publicitaria en la era digital. Daniel Solana.

Veblen, T. (2004) Teoria de la clase ociosa. Madrid. Ed. Alianza.

Verdú, V. (2003) El estilo del mundo. Barcelona. Ed. Anagrama.

Vidal, P. (1985). Una aproximación a la gramática de relatos. En Memoria Académica Extraordinaria del Instituto Fe y Secularidad. Madrid. Vidal, P. (1986). La comprensión por el niño de la intención del mensaje publicitario. Infancia y aprendizaje. Madrid. Ed. A Aprendizaje, SA. 